\title{
Sensitivity of surface radiation budget to clouds over the Asian monsoon region
}

\author{
S BALACHANDRAN ${ }^{1, *}$ and M RAJEEVAN ${ }^{2}$ \\ ${ }^{1}$ Regional Meteorological Centre, Chennai. \\ ${ }^{2}$ National Climate Centre, India Meteorological Department, Pune 400005. \\ *e-mail: balaimd@gmail.com
}

Using the ISCCP-FD surface radiative flux data for the summer season (June to September) of the period 1992 to 1995, an analysis was done to understand the role of clouds on the surface radiation budget over the Asian monsoon region. At the top of atmosphere (TOA) of convective regions of the Asian monsoon region, the short wave radiative forcing (SWCRF) and long wave radiative forcing (LWCRF) do not cancel each other resulting in occurrence of the net cloud radiative forcing values exceeding $-30 \mathrm{~W} / \mathrm{m}^{2}$. This type of imbalance between SWCRF and LWCRF at TOA is reflected down on the earth surface-atmosphere system also as an imbalance between surface netcloud radiative forcing (NETCRF) and atmospheric NETCRF.

Based on the regression analysis of the cloud effects on the surface radiation budget quantities, it has been observed that generally, the variance explained by multiple type cloud data is $50 \%$ more than that of total cloud cover alone. In case of SWCRF, the total cloud cover can explain about $3 \%(7 \%)$ of the variance whereas the three cloud type descriptions of clouds can explain about $44 \%(42 \%)$ of the variance over oceanic (land) regions. This highlights the importance of cloud type information in explaining the variations of surface radiation budget. It has been observed that the clouds produce more cooling effect in short-wave band than the warming effect in long-wave band resulting in a net cooling at the surface. Over the oceanic region, variations in high cloud amount contribute more to variations in SWCRF while over land regions both middle and high cloud variations make substantial contributions to the variations in both SWCRF and NETCRF.

\section{Introduction}

Understanding of the cloud-radiation interaction is essential for proper simulation of future climate through climate models. Clouds play an important role in long term climate changes either directly through their impact on the radiative fluxes or indirectly through their interaction with other variables in the climate system. They cover up to $60 \%$ of our planet at any given time. They play a major role in governing how much sunlight reaches the surface, how much sunlight is reflected back up to space, how and where warmth is spread around the globe, how much heat escapes from the surface and atmosphere back into space. Clouds interact with solar radiation as well as the thermal radiation emitted by the earth and atmosphere in the long-wave region. They reduce the net absorption of solar radiation by increasing the earth albedo and they decrease the loss of terrestrial radiation to space by decreasing the effective temperature of the earth. Cloud-radiation feedback can be defined as the impact of the cloud variations on surface climate due to modifications of the radiation balance and the impact of corresponding climate changes on global cloud redistribution. This could be studied by satellite observations as well as through climate model simulations.

Cloud sensitivity which represents the differential response of the radiative fluxes to the changes

Keywords. Surface radiation budget; Short wave radiative forcing; long wave radiative forcing; net cloud radiative forcing. 
in cloud amount and cloud types is a critical factor in the cloud-radiation feedback. Most of the earlier studies on radiative effects of clouds focused on the relationship between the earth radiation budget at the top of the atmosphere (TOA) and total cloud cover (Fung et al 1984; Hartmann et al 1986; Rossow and Lacis 1990). However, other cloud properties such as cloud types and cloud microphysical properties also determine the climate-radiation interaction. The distribution and occurrence frequency of different cloud types could change during climate variations resulting in a climate feedback. The approach of cloud-radiation interaction studies using cloud type information helps in the understanding of different kinds of atmospheric motions and cloud radiative properties. Ackermann et al (1988) showed that anvil clouds in tropical mesoscale convective complexes produce large vertical heating rate gradients altering upward energy and moisture transports in the tropics. The variability of clouds and radiative fluxes on a variety of space and time scales has been used in the evaluation of cloud effects on the radiative budget (Cess 1976; Hartmann and Short 1980; Ohring and Clapp 1980). Different cloud types are most effective in altering the fluxes depending on whether we consider short-wave or long-wave fluxes and whether we consider TOA, surface or in atmosphere fluxes.

The cloud data sets produced by the International Satellite Cloud Climatology Project (ISCCP) (Schiffer and Rossow 1983; Rossow and Schiffer 1991) are useful in regional as well as global investigations of the radiative effects of cloud type variations. Using ISCCP monthly mean cloud properties, Ockert-Bell and Hartmann (1992) (hereafter referred as OH92) carried out the most extensive investigation of cloud type-radiation interaction over TOA by means of multivariable linear regression. Ringer et al (1997) made a similar study on regional scale and showed that although clouds have a net cooling effect in the global, annual mean radiation balance at the TOA and surface, their net effect on regional, seasonal balances is more varied. The magnitude of cloud property variations and their effects on radiation increases strongly with decreasing space/time scales going from global, annual mean to regional monthly means.

Most of the cloud feedback studies concern themselves with the effects of clouds on the TOA fluxes. Yet there are important potential feedbacks that are governed by the effects produced in the atmosphere and at the surface of the earth. The radiation budget at the earth surface controls dynamic processes in the atmospheric boundary layer and the heat storage in upper ocean and soil layers. Zhang and Rossow (1997) characterized the effects of clouds on the zonal mean energy transports and show that clouds tend to reduce the requirements for oceanic energy transport and enhance it for atmospheric energy transport.

In the present study, using the satellite derived cloud and surface radiative flux data, we examine the nature of effects due to clouds on the surface radiation budget quantities, the relative importance of total cloud cover, and its distribution among cloud types for the determination of surface radiation budget over the Asian monsoon region.

\section{Data and analysis method}

The data for the present study are taken from two sources. One is the International Satellite Cloud Climatology Project (ISCCP) which provides cloud parameters from imaging radiometers on operational weather satellites and related meteorological parameters. The second is the ISCCP-FD that provides radiative fluxes at TOA, and surface. The details of these data are given below.

The ISCCP was established in 1982 as part of the World Climate Research Programme (WCRP) to collect and analyze satellite radiance measurements to infer the global distribution of clouds, their properties, and their diurnal, seasonal, and interannual variations. Data collection began on 1 July 1983 and is currently planned to continue through 30 June 2010. The resulting datasets and analysis products are being used to improve understanding and modeling of the role of clouds in climate, with the primary focus being the elucidation of the effects of clouds on the radiation balance. These data can also be used to support many other cloud studies, including understanding of the hydrological cycle. The ISCCP algorithm for the retrieval of cloud parameters developed as a result of inter comparison tests, proceeds in three steps. In the first step, the image pixels are separated into cloudy, marginally cloudy or clear scenes. In the next step, by comparing observed visible reflectance and infrared brightness temperature with the radiative transfer calculations, the cloud top temperature and the cloud optical depth (during daylight) of each of the cloudy/marginally cloudy pixels are determined. Using TIROS Operational Vertical Sounder (TOVS) temperature profiles, the cloud top pressure is determined from cloud top temperature. In the final step, all the results from each satellite are reduced to a spatial resolution of $2.5^{\circ} \times 2.5^{\circ}(280 \mathrm{~km}$ grid cell $)$ region. This is done by collecting statistics (mean, standard deviation and frequency distribution) of the spatial variability of the surface and clouds and by merging the results from all the satellites. The statistics in terms of cloud types, determined by the 
cloud top pressure and cloud optical depth, are also prepared. These data of the entire globe for every three hours are called stage D-1 data. The cloud data utilized in the study are taken from ISCCPD2 data set, which is the monthly version of the ISCCP-D1 cloud data set.

Another data set is the monthly TOA and surface radiative budget data known as ISCCP-FD data (Zhang et al 2004). The radiative fluxes are derived at TOA, surface and in atmosphere using ISCCP-D2 data and ancillary data sets and a more advanced NASA Goddard Institute for Space Studies (GISS) Radiative transfer model (radiation component of GISS GCM (Hansen et al 2002)). The radiative fluxes are derived at $2.5^{\circ} \times 2.5^{\circ}$ grid size for the period June 1983-June 2001. The basic approach is to collect global measurements on properties of the clouds, atmosphere and surface and to put them into a radiative transfer model to calculate the radiative fluxes at the top of the atmosphere, at the surface and at several levels within the atmosphere. The radiative model is the NASA Goddard Institute for space studies (GISS) radiative model. In this model, apart from top of the atmosphere and surface fluxes, by combining ISCCP cloud information with climatology of cloud vertical structure (Wang et al 2000), fluxes were derived for atmosphere also. This new model (known as 03 model) is an updated version of the old model (known as 95-model) with improved quality of input datasets. The new model has higher spectral resolution. In the SW (0.2 to $5.0 \mu \mathrm{m}$ ) band, the new model has 15 noncontiguous correlated $\kappa$ intervals and 33 noncontiguous correlated $\kappa$ intervals for LW (normally 5.0 to $200 \mu \mathrm{m}$ ) band to model overlapping cloud aerosol and gaseous absorption. With more $\kappa$ spectral intervals to treat the atmosphere and its constituents including aerosols and clouds and surface properties, the new '03-model' has greater accuracy than the '95model'. In new GISS model, the surface albedo values are revised with reflectance from ISCCP-D1 dataset that reduced the global mean clear sky surface albedo for land by about $1 \%$ compared with the old GISS model. In case of ocean albedo, the effect of foam and hydrosols are included in the 03 -model. New $5^{\circ} \times 4^{\circ}$ monthly mean climatology of aerosol vertical profiles for the stratosphere and troposphere were used for atmospheric properties in the 03-model. While TOVS filled with SAGE climatology is used for atmospheric temperature profile, surface air temperature data were extrapolated logarithmically from atmospheric temperature profile with diurnal adjustment. For cloud properties, the ISCCP-D series data for 15 type clouds were used. The ISCCP-FD dataset provides global radiative flux profiles at temporal intervals of 3 hours at 280 spatial resolution on an equal area map and five pressure levels (surface, $680 \mathrm{hPa}$, $440 \mathrm{hPa}, 100 \mathrm{hPa}$ and top of the atmosphere). At each level, upwelling and downwelling, full sky and cloudy sky, SW and LW fluxes are derived. The details of the model, sensitivity to input parameters and evaluation studies are given in Zhang et al (2004). The overall uncertainty in the ISCCP-FD data for regional and monthly means, is about $5-10 \mathrm{Wm}^{-2}$ in TOA flux and $10-15 \mathrm{Wm}^{-2}$ in the surface flux.

In the present study, we use the analysis method similar to that of OH92 in which cloud-radiation interaction was studied at TOA using multiple linear regressions. Multiple liner regression attempts to explain a dependent variable $(y)$ in terms of several independent variables $(x)$ :

$$
\begin{aligned}
& y=b_{0}+b_{1} x_{1}+b_{2} x_{2}+b_{3} x_{3}+\cdots \cdots+b_{n} x_{n} \\
& y=b_{0}+\sum_{i=1}^{n} b_{i} x_{i},
\end{aligned}
$$

where $b_{0}=$ intercept and $b_{i}=$ regression coefficients associated with each independent variable ' $i$ '. Multiple liner regression was used to determine the sensitivity of the surface cloud radiative forcing to cloud type and its vertical distribution.

\section{Results and discussion}

As mentioned earlier, clouds have a radiative effect in both short-wave (SW) and long-wave (LW) regions. Cloud Radiative Forcing (CRF), which refers to difference between the radiative fluxes with and without cloud, has been used to study the impact of clouds on climate. Surface CRF is defined as the difference between surface radiative fluxes under clear sky and cloud sky conditions. Its short wave component is defined as

$$
\operatorname{SWCRF}(S)=F(S)_{\mathrm{SW}}-F(S)_{\mathrm{SW}}^{\mathrm{CL}},
$$

where

$F(S)_{\mathrm{SW}}=$ Net SW radiation flux at surface under cloudy sky condition,

$F(S)_{\mathrm{SW}}^{\mathrm{CL}}=$ Net SW radiation flux at surface under clear sky condition.

Similarly, the long wave component of surface CRF can be defined as

$$
\operatorname{LWCRF}(S)=F(S)_{\mathrm{LW}}-F(S)_{\mathrm{LW}}^{\mathrm{CL}}
$$

where

$$
\begin{aligned}
F(S)_{\mathrm{LW}}= & \text { Net } \mathrm{LW} \text { radiation flux at surface under } \\
& \text { cloudy sky condition, } \\
F(S)_{\mathrm{LW}}^{\mathrm{CL}}= & \text { Net } \mathrm{LW} \text { radiation flux at surface under } \\
& \text { clear sky condition. }
\end{aligned}
$$


The net CRF at the surface is simply the sum of the SWCRF and LWCRF defined above, i.e.,

$$
\operatorname{NETCRF}(S)=\operatorname{SWCRF}(S)+\operatorname{LWCRF}(S)
$$

Similar to (1), (2) and (3), the SWCRF, LWCRF and NETCRF can be defined for top of the atmosphere (TOA) and for atmosphere (A).

The top of the atmosphere, surface and atmospheric CRF are related as

$$
\operatorname{NETCRF}(A)=\operatorname{NETCRF}(T)-\operatorname{NETCRF}(S)
$$

Generally, the downward fluxes are considered as positive and upward fluxes are negative. Positive values of CRF parameters indicate a warming of the system and negative values indicate cooling of the system. The downward fluxes $F(S)_{\mathrm{SW}}$ and $F(S)_{\mathrm{SW}}^{\mathrm{CL}}$ are positive and generally $F(S)_{\mathrm{SW}}^{\mathrm{CL}}$ is greater than $F(S)_{\text {SW }}$ and thus making $\operatorname{SWCRF}(S)$ a negative quantity. On the other hand, both $F(S)_{\mathrm{SW}}$ and $F(S)_{\mathrm{LW}}^{\mathrm{CL}}$ are negative but in magnitude generally $F(S)_{\mathrm{LW}}^{\mathrm{CL}}$ is greater than $F(S)_{\mathrm{SW}}$, which makes LWCRF a negative quantity. Generally, therefore, SWCRF results in a cooling at the surface and LWCRF results in a warming at the surface. The nature of NETCRF at TOA as well as at surface over the Asian monsoon region is discussed below.

\subsection{Spatial patterns of cloud radiative forcing at TOA}

Based on the data from ERBE, Kiehl and Ramanathan (1990) and Kiehl (1994) concluded that the cloud induced changes in both SW fluxes and LW fluxes in tropical convective regions were of the same magnitude but of the opposite sign. This leads to near cancellation of SWCRF and LWCRF resulting value of NETCRF close to zero. Rajeevan and Srinivasan (2000), using satellite measured data (ERBE) for a limited period (1985-1988), showed that this type of cancellation is invalid over the Asian monsoon region $\left(0^{\circ}\right.$ to $30^{\circ} \mathrm{N}$ and $60^{\circ} \mathrm{E}$ to $120^{\circ} \mathrm{E}$ ) and NETCRF value exceeds $-30 \mathrm{~W} / \mathrm{m}^{2}$. This is due to the presence of a large amount of high cloud and large optical depth over this region. Sathiyamoorthy et al (2004) suggested that the unique upper-tropospheric easterly wind shear present over during the summer monsoon season may be responsible for the unusual high cloud amount over the Asian monsoon region.

We have further examined these cloud radiative forcing patterns using ISCCP-FD data for more observed years 1984 to 2000. The spatial pattern of SWCRF, LWCRF and NETCRF at the TOA for the period June-September averaged over the period 1984-2000 using ISSCP-FD data is shown in figure 1. Large values of SWCRF exceeding $100 \mathrm{~W} / \mathrm{m}^{2}$ are seen over north Bay of Bengal and adjoining land areas of east Asia. The large values of LWCRF are noted over the Bay of Bengal and the eastern Indian Ocean. The negative values of NET cloud forcing exceeding $30 \mathrm{~W} / \mathrm{m}^{2}$ are observed over parts of Arabian Sea, most parts of Indian land mass, northern Bay of Bengal and adjoining east Asian land mass. These features as revealed from the radiative transfer model generated analysis are similar as those reported by Rajeevan and Srinivasan (locit.) using the ERBE data. Thus there exists imbalance between SWCRF and LWCRF at the TOA over the Asian monsoon region.

\subsection{Relationship between surface NETCRF and atmospheric NETCRF}

The CRF at the TOA represents the overall radiative effect of clouds on the surface-atmosphere system. Any change in the radiational energy input at TOA will have an effect further down on the earth's surface as well on the atmosphere. Hence the imbalance between SWCRF and LWCRF at TOA discussed above, will reflect in the surface as well as atmosphere where clouds register their effects on the energetics of the system.

The scatter plots relating surface NETCRF and atmospheric NETCRF in the Asian monsoon region $\left(0^{\circ}-30^{\circ} \mathrm{N}, 60^{\circ}-120^{\circ} \mathrm{E}\right)$ based on ISCCP-FD data for the period June-September during 19851989 are shown in figure 2 for ocean and land points separately. This highlights the imbalance between surface NETCRF and atmospheric NETCRF over Asian monsoon region and hence reflection of the condition existing at the top of the atmosphere over this region as discussed earlier. As shown in figure 2, the surface NETCRF is in near balance with atmospheric NETCRF when atmospheric NETCRF is less than $50 \mathrm{~W} / \mathrm{m}^{2}$ over the ocean. The surface NETCRF is larger than atmospheric NETCRF when atmospheric NETCRF is more than $50 \mathrm{~W} / \mathrm{m}^{2}$. The land points also indicate the nonlinear relationship between surface NETCRF and atmospheric NETCRF. Further insights on the imbalance between surface SWCRF and atmospheric LWCRF can be ascertained from the following analysis of the frequency distribution of these CRF values.

\subsection{Frequency distributions of surface and atmosphere NETCRF}

The frequency distribution of surface NETCRF, atmospheric NETCRF and combination of these two (i.e., surface NETCRF + atmosphere NET$\mathrm{CRF}$ ) over the Asian monsoon region are shown 
SWCRF

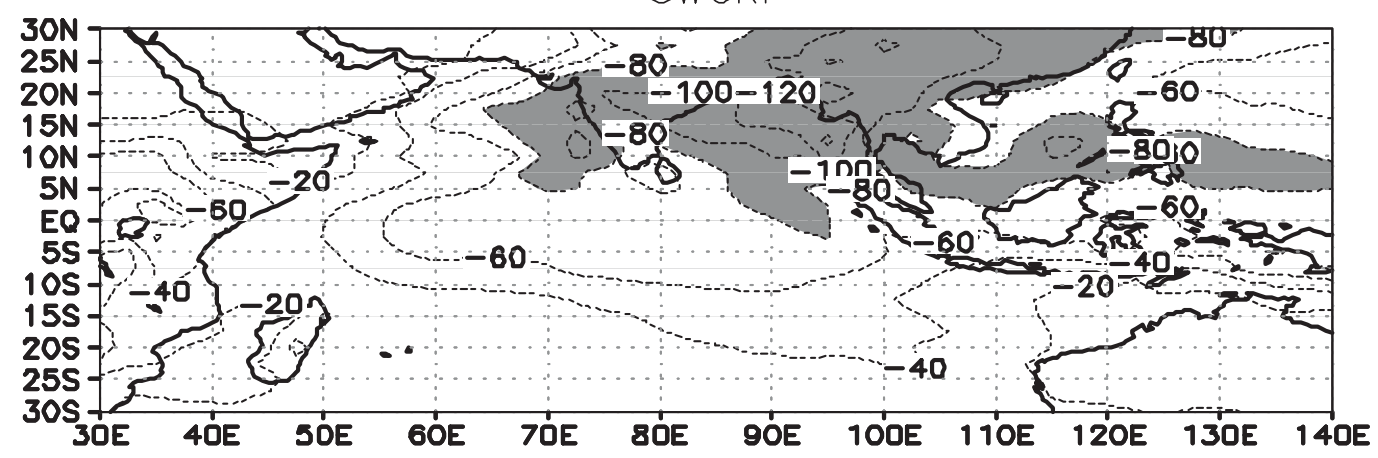

LWCRF

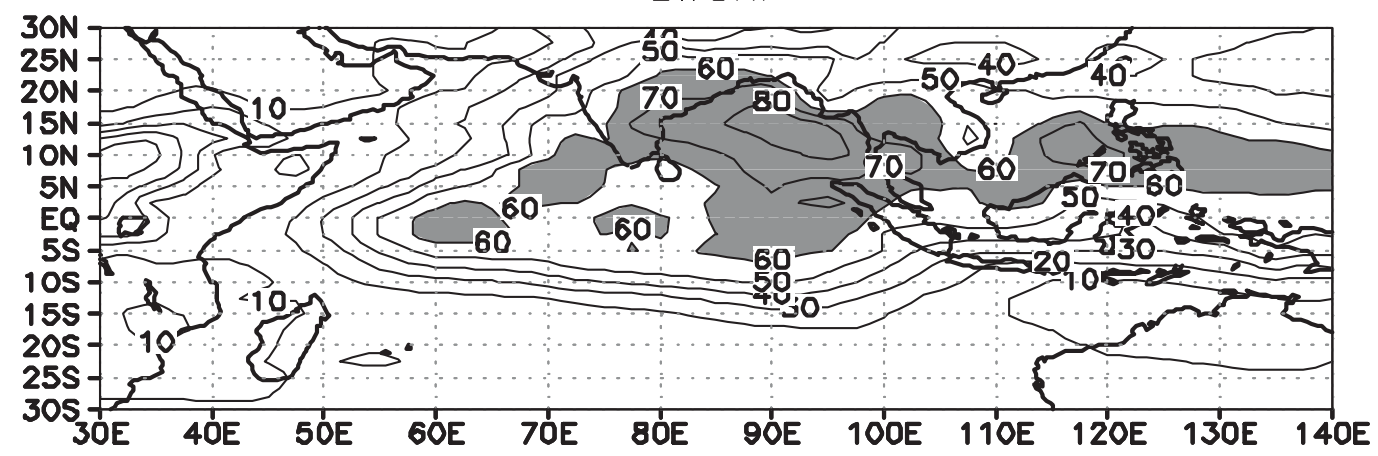

NETCRF

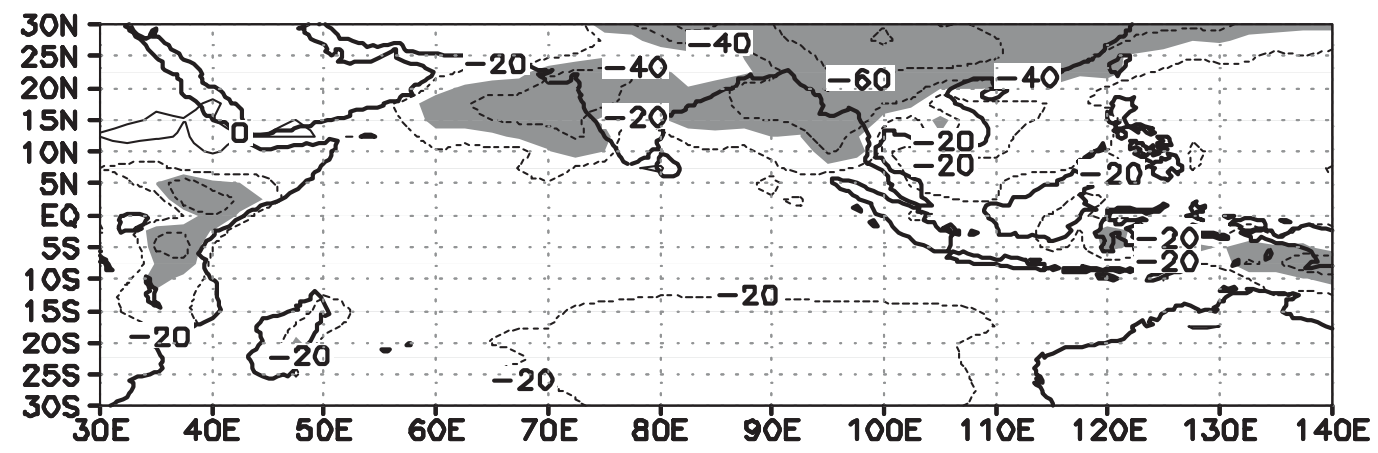

Figure 1. Spatial variation of average SWCRF, LWCRF and NETCRF in $\mathrm{W} / \mathrm{m}^{2}$ at top of atmosphere. Period: June-September 1984-2000. SWCRF exceeding $80 \mathrm{~W} / \mathrm{m}^{2}$, LWCRF exceeding $60 \mathrm{~W} / \mathrm{m}^{2}$ and NETCRF exceeding $30 \mathrm{~W} / \mathrm{m}^{2}$ shaded.

in figure 3 for land and ocean regions separately. While there exists considerable percentage of points with surface NETCRF lower than $-90 \mathrm{~W} / \mathrm{m}^{2}$, the percentage of points with atmospheric NETCRF more than $90 \mathrm{~W} / \mathrm{m}^{2}$ is negligible. This asymmetry in the frequency distribution of surface NETCRF and atmospheric NETCRF leads to the asymmetry in the frequency distribution on the combined earth surface and atmosphere NETCRF. The frequency distribution of combined surface NETCRF and atmospheric NETCRF shows maximum around $10 \mathrm{~W} / \mathrm{m}^{2}$ but there is a long tail indicating the existence of regions with large negative cloud forcing values over both land and ocean. In fact, occurrence of such large negative cloud forcing values are more during the summer season compared to other seasons which is illustrated in the following discussion.

The seasonal variation of NETCRF at the surface over the Asian monsoon region for four seasons are shown in figure 4. From this figure, it is observed that the frequency distribution of NETCRF shifts to values of higher magnitude during the summer season as compared with other seasons. Frequency of NETCRF with magnitude exceeding $100 \mathrm{~W} / \mathrm{m}^{2}$ is less than $5 \%$ during winter, 

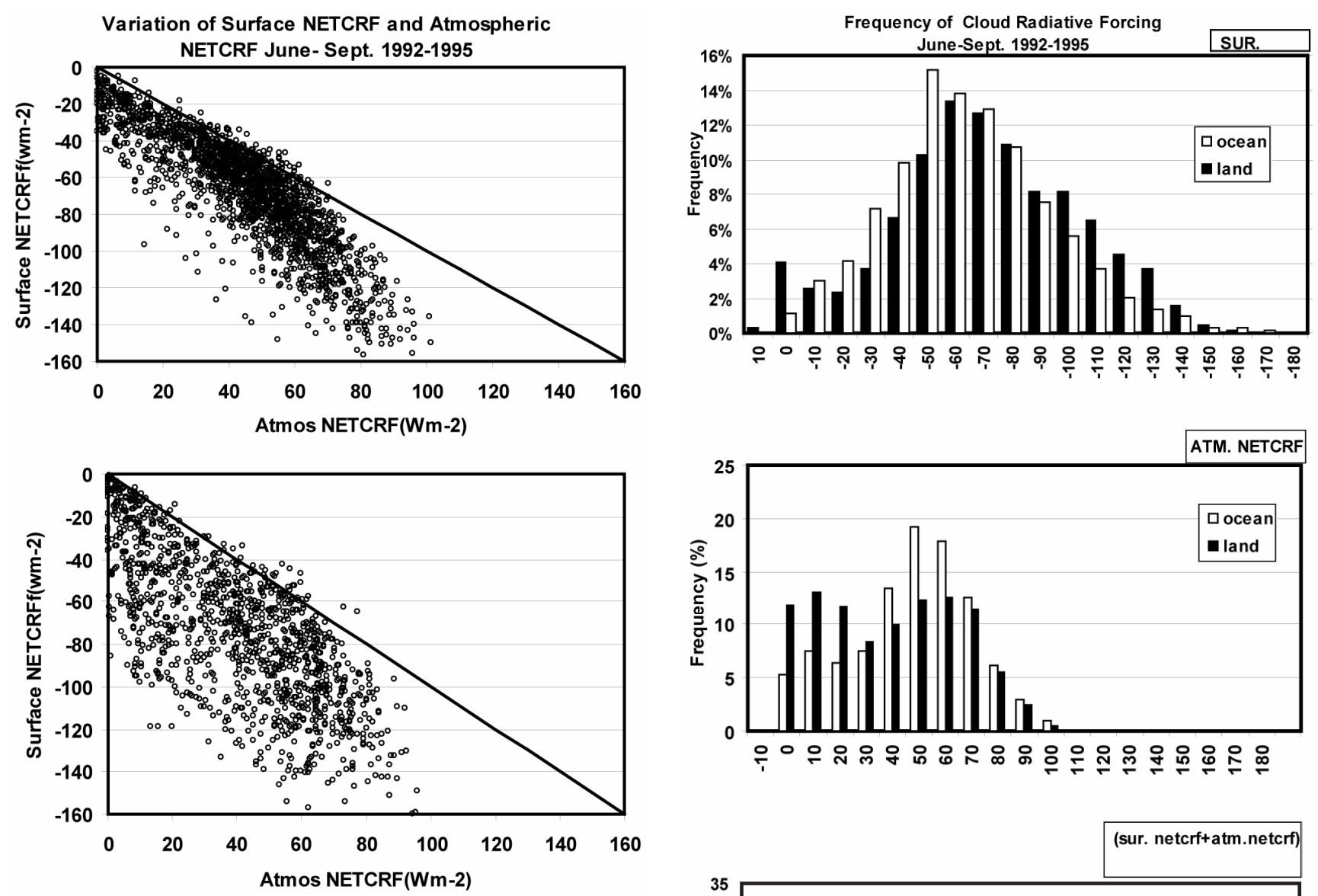

Figure 2. Scatter relationship between surface NETCRF and atmospheric NETCRF for land and oceanic regions. Period: June-September 1992-1995. Region: $0^{\circ}-30^{\circ} \mathrm{N}$, $60^{\circ}-120^{\circ} \mathrm{E}$.

spring and autumn seasons. However, during the summer season, the percentage of grid points with NETCRF of magnitude greater than $100 \mathrm{~W} / \mathrm{m}^{2}$ is about $27 \%$. Thus large negative NETCRF occurs at surface during the monsoon season in comparison with other seasons over the Asian monsoon region.

\subsection{Spatial patterns of surface cloud radiative forcing}

The spatial patterns of SWCRF, LWCRF and NETCRF at the surface for the season JuneSeptember during the period 1984-2000 using ISSCP-FD data are shown in figure 5 . Values of negative SWCRF exceeding $100 \mathrm{Wm}^{-2}$ in magnitude are observed over the Indian land mass, Bay of Bengal and adjoining Asian land mass. Due to atmospheric LW absorption, the effect of clouds on surface in LW band is only marginal and hence LWCRF values are considerably very small over this region. Hence, the distribution of NETCRF values shows features similar to that of SWCRF over this region.

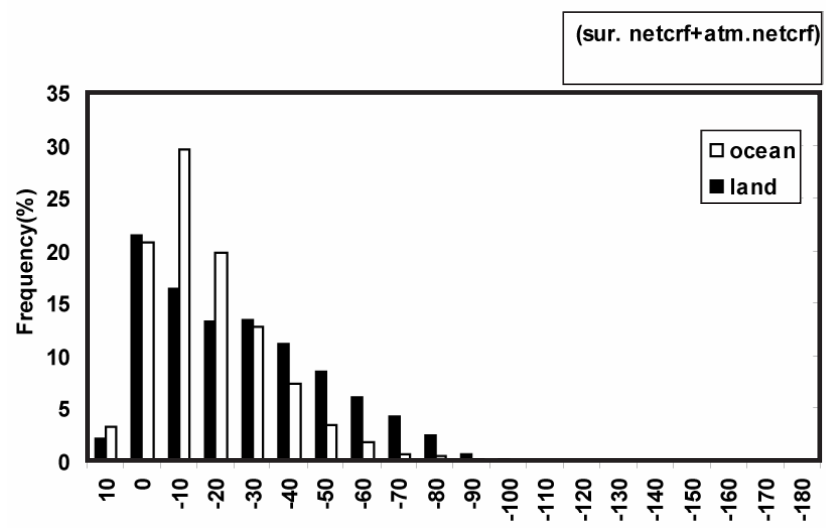

Figure 3. Frequency distribution (in \%) of surface NETCRF, atmospheric NETCRF and combination of these two (i.e., surface NETCRF + atmospheric NETCRF) for $10 \mathrm{~W} / \mathrm{m}^{2}$ interval for land and oceanic regions. Period: June-September $1992-1995$. Region: $0^{\circ}-30^{\circ} \mathrm{N}, 60^{\circ}-120^{\circ} \mathrm{E}$.

Bergman et al (2000) showed that the CRF contributes about $20 \%$ to the magnitude of low latitude circulations. It influences local circulations more and reinforces the circulation that is driven by convective latent heating. Randall et al (1989) examined the role of upper tropospheric clouds on both convection and general circulation using the general circulation model and showed that increased cloudiness over the tropics leads to moistening and deepening of the boundary layer along with intensification of the mean meridional circulation. The cloud induced local imbalances 


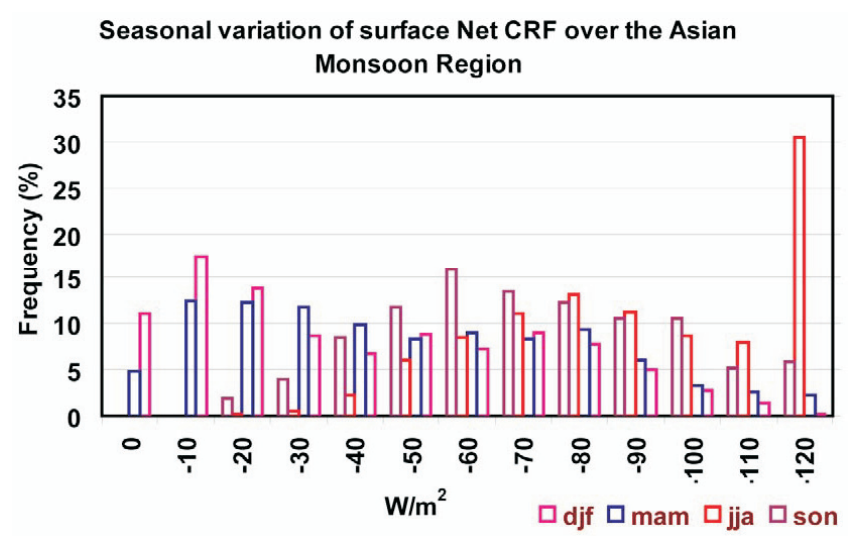

Figure 4. Frequency distribution (in \%) of ISCCP-FD surface net cloud radiative forcing for $10 \mathrm{~W} / \mathrm{m}^{2}$ interval for December-January, March-May, June-September, and October-December period: June-September 1992-1995. Region: $0^{\circ}-30^{\circ} \mathrm{N}, 60^{\circ}-120^{\circ} \mathrm{E}$.

between SW and LW terms introduce significant changes in the local radiation balance that results in north-south and east-west gradients in net radiation. The large cooling effect at the surface during the monsoon season will affect vertical temperature gradient and hence play an important role in the boundary layer process as well as vertical stability of the atmospheric column over this region. Thus, the large negative NETCRF over the Asian monsoon region has further implications on the circulation over this region and hence we intend to examine cloud type-cloud radiative forcing at the surface over the Asian monsoon region.

\subsection{Regression analysis of surface radiative budget quantities}

The radiative effects of clouds depend not only on the fractional coverage but also on their type and vertical distribution. Multiple linear regression analysis could be used to evaluate the effect of cloud on the radiation budget quantities. Based on (1), the regression equations are of the form:

$$
R=R_{0}+\sum_{i=1}^{n} a_{i} c_{i}
$$

where $R=$ cloud radiative forcing under consideration (e.g., SWCRF), $R_{0}=$ intercept, $a_{i}=$ regression coefficient describing the effect of cloud type ' $i$ ' ' on the cloud radiative forcing quantity $R$, and $C_{i}=$ amount of cloud type ' $i$ '.

We consider anomalies of surface SWCRF, LWCRF and NETCRF monthly data derived from ISCCP-FD data for June to September 1992 over the region 0 to $30^{\circ} \mathrm{N}$ and $60^{\circ} \mathrm{E}$ to $120^{\circ} \mathrm{E}$ for the regression analysis. We also use corresponding ISCCP-D2 low, middle, high and total cloud anomalies for the same period. The results are given in Tables 1, 2(a) and 2(b). Mean and standard deviation of low, middle, high cloud, SWCRF, LWCRF and NETCRF anomalies as well as mean and standard deviation of total cloud anomalies are given in Tables 2(a) and 2(b). Also the regression coefficients for three-type clouds (low, middle and high clouds) and one type cloud (total cloud) and the explained variance by each cloud type predictor are shown in the same tables. Using these tables, the role of cloud types in the surface CRF quantities during the monsoon season is discussed below.

The comparison between the variance explained by regression on total cloud anomalies alone with variance explained by regression on cloud types (low, middle and high) indicate the utility of multiple regression in the understanding of cloud height dependence of cloud-radiation interaction. Table 1 shows a significant increase in the explained variance of SWCRF, LWCRF and NETCRF at surface by dividing total cloud coverage into contributions from different cloud types. Generally the variance explained by multiple type cloud data is $50 \%$ more than that of total cloud cover alone. In the case of SWCRF, the total cloud cover can explain about $3 \%(7 \%)$ of the variance whereas the three cloud type descriptions of clouds can explain about $44 \%$ $(42 \%)$ of variance over oceanic (land) regions. The high cloud variations show more influence than low and middle clouds on SWCRF. The single parameter regression with high clouds alone explains as much of the explained variance as the three cloud type multiple regression and more than the regression on total cloud coverage alone. In the case of LWCRF, multiple, single type regression as well as regression on total cover does not show a significant amount of explained variance. The results for NETCRF are similar to those of SWCRF with high cloud playing a dominant role in the explained variance.

\subsection{Sensitivity of surface CRF to clouds}

The sensitivity of the surface CRF quantities at surface to the cloud types over the Asian monsoon region could be evaluated using the values of regression coefficients. The regression coefficients in Tables 2(a) and 2(b) illustrate that cloud produce a cooling effect in SW band and a warming effect in the LW band at the surface. Clouds decrease the solar radiation absorbed at the surface due to the albedo effect. By means of the greenhouse effect, the clouds trap the outgoing $\mathrm{LW}$ radiation. The abundance of moisture in the atmosphere makes the atmosphere strongly absorptive to $L W$ radiation. As a result the downward LW fluxes are absorbed by atmosphere and only 
SWCRF

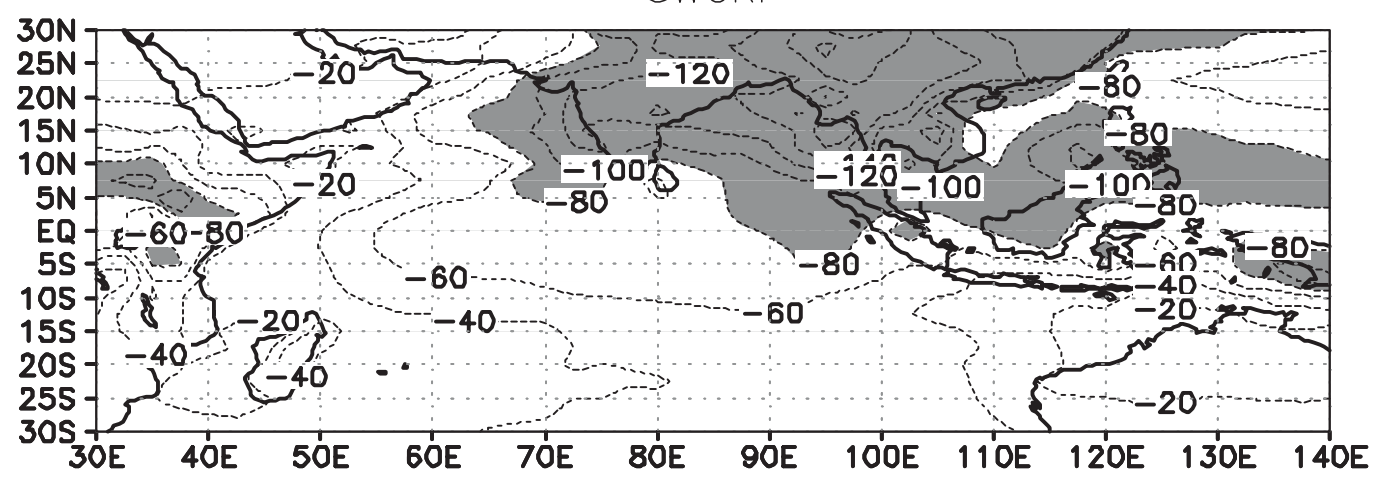

LWCRF

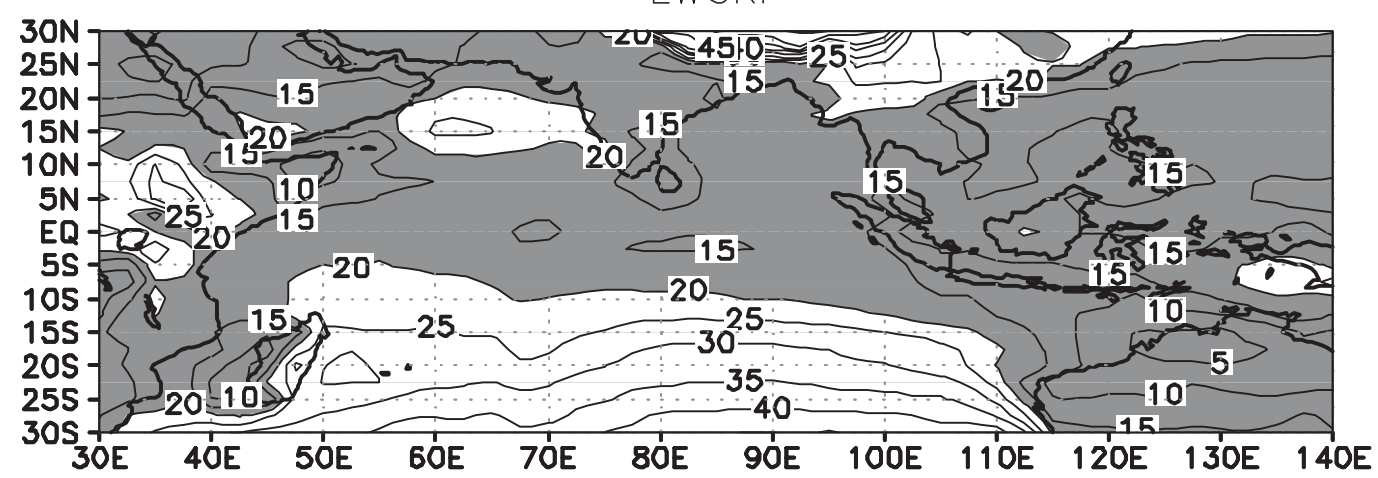

NETCRF

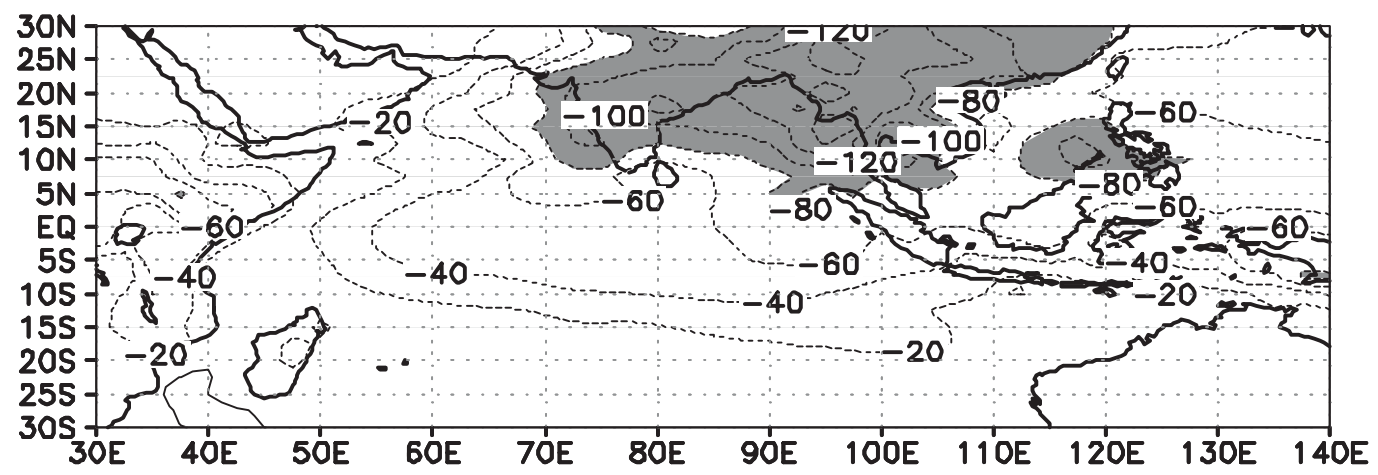

Figure 5. Spatial variation of average SWCRF, LWCRF and NETCRF in $\mathrm{W} / \mathrm{m}^{2}$ at surface. Period: June-September 1984-2000. SWCRF exceeding $80 \mathrm{~W} / \mathrm{m}^{2}$, LWCRF less than $15 \mathrm{~W} / \mathrm{m}^{2}$ and NETCRF exceeding $30 \mathrm{~W} / \mathrm{m}^{2}$ shaded.

marginally felt at the surface. This results in dominance of SW cooling over LW warming at surface. Over the oceanic region, variations in high cloud amount contribute more to variations in SWCRF while over land regions both middle and high cloud variations make substantial contributions to the variations in both SWCRF and NETCRF. The sensitivities of SWCRF and NETCRF for low clouds are larger over sea than over land. This is due to the large difference between clear sky and cloudy sky planetary albedos over oceans. Another factor may be the uncertainties in the ISCCP low cloud estimates over land due to highly variable albedo over land regions.

The sensitivities of LWCRF for low, middle and high clouds are very small compared to those of SWCRF and this leads to the dominance of SWCRF cooling over LWCRF warming resulting in NETCRF cooling.

In the case of surface NETCRF, the high clouds have large sensitivity coefficient compared with low and higher clouds. The scatter plots of SWCRF 
Table 1. Explained variance obtained from regressions of the anomalies of CRF at surface and cloud anomalies during June to September for the period 1992-1995 for ocean and land regions of Asian monsoon region $\left(0^{\circ}-30^{\circ} N, 60^{\circ}-120^{\circ} E\right) . R^{2}\left(\Delta C_{L}\right), R^{2}\left(\Delta C_{M}\right), R^{2}\left(\Delta C_{H}\right)$, and $R^{2}\left(\Delta C_{T C}\right)$ are the explained variances (in per cent) obtained from linear regressions on low-, middle-, high- and total-cloud anomalies alone. $R^{2}(M R)$ (in per cent) is that obtained from multiple linear regression using low-, middle-, and high-cloud anomalies together.

\begin{tabular}{lccccc}
\hline Region & $R^{2}\left(\Delta C_{L}\right)$ & $R^{2}\left(\Delta C_{M}\right)$ & $R^{2}\left(\Delta C_{H}\right)$ & $R^{2}\left(\Delta C_{T}\right)$ & $R^{2}(M R)$ \\
\hline Ocean & 5 & 0 & 37 & 3 & 44 \\
SWCRF & 1 & 7 & 0 & 8 & 13 \\
LWCRF & 7 & 0 & 41 & 2 & 46 \\
NETCRF & & 5 & & 7 & 42 \\
\hline Land & 0 & 12 & 0 & 4 & 13 \\
SWCRF & 1 & 3 & 30 & 6 & 45 \\
LWCRF & 0 & & & & \\
NETCRF & & & & & \\
\hline
\end{tabular}

Table 2. (a) The mean and standard deviation (SD) for the low cloud, middle cloud, high cloud, SWCRF, LWCRF and NETCRF anomalies during June to September for the period 1992-1995 over oceanic regions of the Asian monsoon region $\left(0^{\circ}-30^{\circ} \mathrm{N}, 60^{\circ}-120^{\circ} \mathrm{E}\right) .\left(a_{0}\right)$ and $\left(a_{i}\right)$ are the intercept and regression coefficients for the three cloud type; $\left(b_{0}\right)$ and $\left(b_{i}\right)$ are the intercept and regression coefficient for total cloud cover. (b) Same as 2(a) except for the land regions of the Asian monsoon region $\left(0^{\circ}-30^{\circ} \mathrm{N}, 60^{\circ}-120^{\circ} \mathrm{E}\right)$.

(a)

\begin{tabular}{lcr}
\hline & Mean & SD \\
\hline Low cloud (\%) & -1.8 & 5.5 \\
Medium cloud (\%) & -0.20 & 3.9 \\
High cloud (\%) & 5.45 & 8.8 \\
Total cloud (\%) & 0.29 & 10.1 \\
SWCRF $\left(\mathrm{Wm}^{-2}\right)$ & -1.7 & 15.6 \\
LWCRF $\left(\mathrm{Wm}^{-2}\right)$ & 0.24 & 2.1 \\
NETCRF $\left(\mathrm{Wm}^{-2}\right)$ & -1.46 & 14.7 \\
& \multicolumn{2}{c}{ Reg. coefficient }
\end{tabular}

Surface SWCRF

$\begin{array}{cr}a_{0} & 4.60 \\ a_{L} & -0.58 \\ a_{M} & -0.79 \\ a_{H} & -1.40 \\ b_{0} & -1.62 \\ b_{T C} & -0.28\end{array}$

Surface LWCRF

$\begin{array}{cc}a_{0} & 0.50 \\ a_{L} & 0.09 \\ a_{M} & 0.16 \\ a_{H} & 0.07 \\ b_{0} & 0.22 \\ b_{T C} & 0.06\end{array}$

Surface NETCRF

$\begin{array}{cr}a_{0} & 4.70 \\ a_{L} & -0.49 \\ a_{M} & -0.63 \\ a_{H} & -1.32 \\ b_{0} & -1.40 \\ b_{T C} & -0.22\end{array}$

(b)

\begin{tabular}{lrr}
\hline & Mean & SD \\
\hline Low cloud (\%) & 2.7 & 10.0 \\
Medium cloud (\%) & 0.4 & 4.9 \\
High cloud (\%) & 2.4 & 8.5 \\
Total cloud (\%) & 0.9 & 9.4 \\
SWCRF $\left(\mathrm{Wm}^{-2}\right)$ & -1.4 & 17.7 \\
LWCRF $\left(\mathrm{Wm}^{-2}\right)$ & 0.9 & 3.2 \\
NETCRF $\left(\mathrm{Wm}^{-2}\right)$ & $-0.4 \quad$ & 16.8 \\
& \multicolumn{2}{c}{ Reg. coefficient }
\end{tabular}

Surface SWCRF

$\begin{array}{cr}a_{0} & 3.46 \\ a_{L} & -0.34 \\ a_{M} & -1.46 \\ a_{H} & -1.42 \\ b_{0} & -0.95 \\ b_{T C} & -0.50\end{array}$

Surface LWCRF

$\begin{array}{cc}a_{0} & 0.94 \\ a_{L} & 0.03 \\ a_{M} & 0.22 \\ a_{H} & 0.01 \\ b_{0} & 0.89 \\ b_{T C} & 0.06\end{array}$

Surface NETCRF

$\begin{array}{cr}a_{0} & 4.36 \\ a_{L} & -0.37 \\ a_{M} & -1.23 \\ a_{H} & -1.40 \\ b_{0} & -0.06 \\ b_{T C} & -0.43\end{array}$



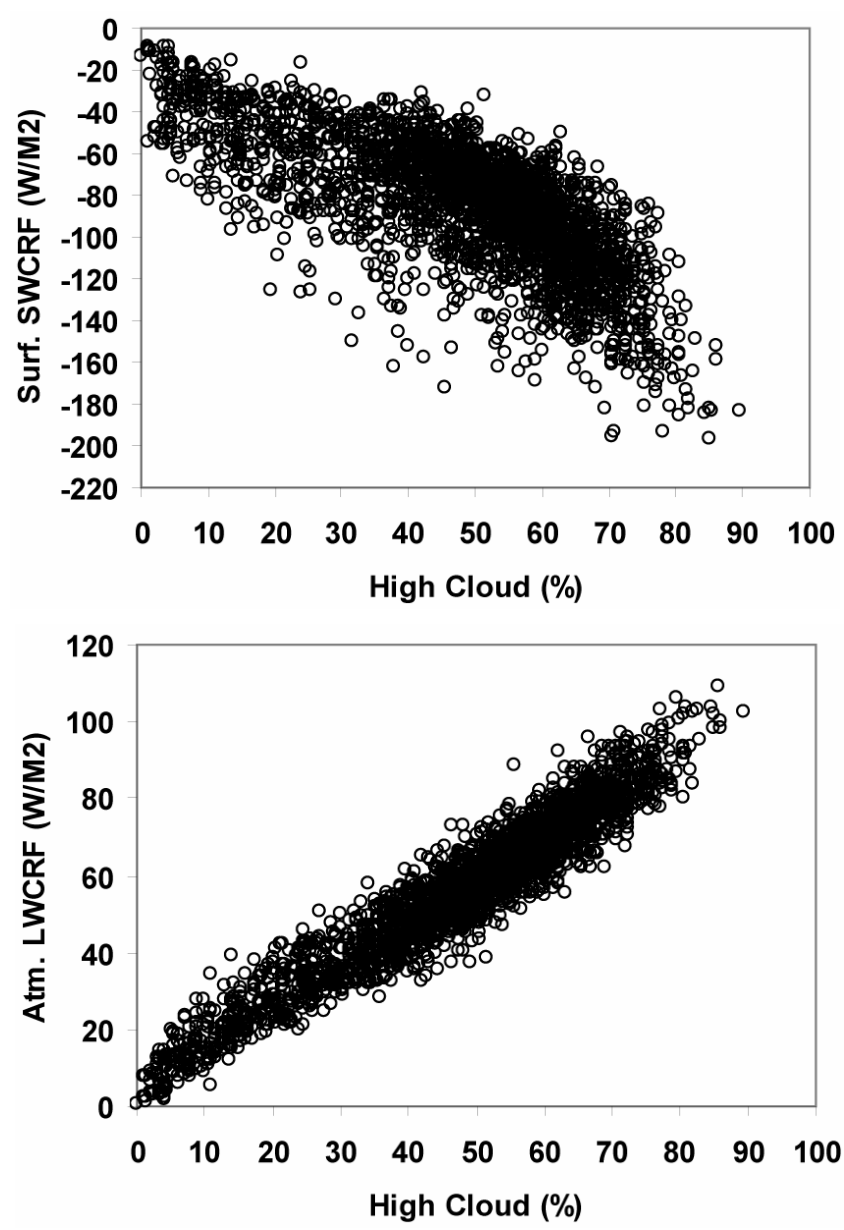

Figure 6. Scatter plot between SWCRF at surface and high cloud amount (top) and frequency of deep convection (bottom). Period: June-September 1992-1995. Region: $0^{\circ}-30^{\circ} \mathrm{N}$, $60^{\circ}-120^{\circ} \mathrm{E}$.

at surface and LWCRF at troposphere with high cloud amount over the Asian monsoon region is shown in figure 6 which illustrates the linear relationships between these CRFs and high cloud.

\section{Conclusions}

Based on the above analysis, the following conclusions can be drawn:

- At TOA of convective regions of Asian monsoon regions, the SWCRF and LWCRF do not cancel each other resulting in occurrence of the net cloud radiative forcing values exceeding $-30 \mathrm{~W} / \mathrm{m}^{2}$. This type of imbalance between SWCRF and LWCRF at TOA is reflected down on the earth surface-atmosphere system as an imbalance between surface NETCRF and atmospheric NETCRF.

- Generally the variance explained by multiple type cloud data on surface radiative flux is
$50 \%$ more than that of total cloud cover alone. In the case of SWCRF, the total cloud cover can explain about $3 \%(7 \%)$ of the variance whereas the three cloud type description of clouds can explain about $44 \%(42 \%)$ of variance over oceanic (land) regions. This indicates the importance of cloud type information in explaining the variations of surface radiative budget.

- From the sensitivity analysis of the surface radiation fluxes to cloud types, it has been observed that the clouds produce more cooling effect in SW band than warming effect in LW band resulting in net flux cooling at the surface over the Asian monsoon region.

- Over the oceanic region, variations in high cloud amount contribute more to variations in SWCRF while over land regions both middle and high cloud variations make substantial contributions to the variations in both SWCRF and NETCRF.

The accuracy of the regression estimates in the present study depends on the assumption that the underlying relationships are linear and that the data utilized span the full possible range of variability. Also there is a possible influence of quality of input data on the analysis carried out. In the case of ISCCP cloud data, the reported middle and low cloud amounts are from the observations from top which may be obscured by higher cloud and there is generally less low cloud in the ISCCP observations than estimated by surface observations. These features may affect the present results. Moreover, recent studies pointed out the role of aerosol loading in the radiation budget over the Asian monsoon region. As shown by Ramanathan et al (2005), the emissions of fossil fuel $\mathrm{SO}_{2}$ and black carbon increased over south Asian region by $\approx 6$ fold since 1930. These aerosols absorb and scatter solar radiation and decrease surface solar radiation flux to the extent of about $-25 \mathrm{Wm}^{-2}$. In the GISS model global, actual and highly variable amounts of aerosols are not considered but monthly mean climatology of aerosol vertical profiles for the stratosphere and troposphere composed of 18 different aerosol sizes were considered for atmospheric properties. Hence notable changes in clear sky fluxes of solar radiation and to some extent also of terrestrial radiation may therefore occur due to additional anthropogenic and natural aerosols. A more detailed model with considerations for changes in clear sky fluxes, the vertical cloud water content, sub-cloud layer temperatures and aerosol loadings with improved cloud detection schemes would improve understanding and modeling of the cloud-radiation interaction over the Asian monsoon region. 


\section{Acknowledgements}

The authors thank the Director General of Meteorology, India Meteorological Department, for providing facilities to undertake this study and for permission to publish in this journal. The authors also wish to thank the anonymous reviewer for useful comments.

\section{References}

Ackerman T P, Liou K N, Valero F P J and Pfister L 1988 Heating rates in tropical anvils; J. Atmos. Sci. 45 1606-1623.

Bergman J W and Hendon H H 2000 Cloud radiative forcing of low-latitude tropospheric circulation: Linear calculations; J. Atmos. Sci. 57(14) 2225-2245.

Cess R D 1976 Climate change: An appraisal of atmospheric feedback mechanisms employing zonal climatology; J. Atmos. Sci. 33 1831-1843.

Fung I Y, Harrison D E and Lacis A A 1984 On the variability of the net longwave radiation at the ocean surface; Rev. Geophys. Space Phys. 22 177-193.

Hansen J et al 2002 Climate forcings in Goddard Institute for space studies SI2000 simulations; J. Geophys. Res. 107(D18) 4347, doi:10.1029/2001JD001143.

Hartmann D L, Ramanathan V, Berrior A and Hunt G E 1986 Earth radiation Budget data and climate research; Rev. Geophys. Space Phys. 24 439-468.

Hartmann D L and Short D A 1980 On the use of earth radiation budget statistics for studies of clouds and climate; J. Atmos. Sci. 37 1223-1250.

Kiehl J T and Ramanathan V 1990 Comparison of cloud forcing derived from the Earth Radiation Budget Experiment with that simulated by the NCAR community climate model; J. Geophys. Res. 95 $11,679-11,698$
Kiehl J T 1994 On the observed near cancellation between longwave and short wave cloud forcing in tropical regions; J. Climate 7 559-565.

Ockert-Bell M E and Hartmann D L 1992 The effect of cloud type of earth's energy balance: Results for selected regions; J. Climate 5 1158-1171.

Ohring G and Clapp P 1980 The effect of changes in cloud amount on the net radiation at the top of the atmosphere; J. Atmos. Sci. 37 447-454.

Rajeevan M and Srinivasan J 2000 Net Cloud Radiative Forcing at the Top of the Atmosphere in the Asian Monsoon Region; J. Climate 13 650-657.

Ramanathan and coauthors 2005 Atmospheric brown clouds: Impacts on South Asian climate and hydrological cycle, www.pnas.org/cgi/doi/10.1073/pnas.0500656102

Rossow W B and Lacis A A 1990 Global, seasonal cloud variations from satellite radiance measurements. Part II: Cloud properties and radiative effects; J. Climate $\mathbf{3}$ 1204-1253.

Rossow W B and Schiffer R A 1991 ISCCP Cloud data products; Bull. Amer. Meteor. Soc. 72 2-20.

Sathiyamoorty V, Pal P K and Joshi P C 2004 Influence of the upper-tropospheric wind shear upon cloud radiative forcing in the Asian monsoon region; J. Climate 17(14) 2725-2735.

Schiffer R A and Rossow W B 1983 The International Satellite Cloud Climatology Project (ISCCP): The first project of the World Climate Research Programme; Bull. Amer. Meteor. Soc. 64 779-784.

Wang J, Rossow W B and Zhang Y C 2000 Cloud vertical structure and its variation from 20-yr global rawinsonde dataset; J. Climate 12 3041-3056.

Zhang Y C and Rossow W B 1997 Estimating meridional energy transports by the atmospheric and oceanic general circulations using boundary fluxes, J. Climate 10 2358-2373.

Zhang Y C, William B Rossow, Andrew A Lacis, Valdar Oinas and Michael I Mishchenko 2004 Calculation of radiative fluxes from the surface to top of atmosphere based on ISCCP and other global data sets: refinements of the radiative model and the input data, J. Geophys. 109 D19105, doi:10.1029/2003. 